\title{
Dos direitos dos governados em Michel Foucault
}

\author{
About the rights of the governed in Michel Foucault
}

Los derechos de los gobernados en Michel Foucault

\author{
Rodrigo Diaz de Vivar y Soler
}

\section{Universidade Regional de Blumenau (FURB), Blumenau, SC, Brasil}

\begin{abstract}
Resumo
Nosso artigo procura pensar os direitos dos governados em Michel Foucault como uma crítica à governamentalidade e à biopolítica. Em um primeiro momento, é apresentada uma breve exposição sobre as possíveis correlações entre uma história política da governamentalidade e os processos de condução das condutas produzidas por práticas refletidas de governo, a partir de Foucault. Em um segundo momento, destacamos a emergência da biopolítica e dos modos de condutas do liberalismo e do neoliberalismo, na formação do que Foucault chama de modulação de modos de subjetivação tipicamente econômicos. O terceiro momento do artigo é dedicado a pensar as insurreições dos direitos dos governados como estratégias de resistências aos processos de governamentalização da vida. Nossas considerações finais apontam para os tensionamentos das insurreições dos governados como uma forma de vida contrária às diretrizes econômicas da governamentalidade e da biopolítica, por meio do que Foucault chama de política espiritual da revolta.
\end{abstract}

Palavras-chave: Direitos dos governados; Michel Foucault; Biopolítica; Governamentalidade.

\begin{abstract}
This papper seeks to think of the governed rights in Michel Foucault as a critique of governmentality and biopolitics. At first, a brief exposition is presented about the possible correlations between a political history of governmentality and the conduction processes of behavior produced by reflected practices of government from Foucault. Secondly, we highlight the emergence of the biopolitics and modes of conduct of liberalism and neoliberalism, in the formation of what Foucault calls the modulation of typically economic modes of subjectivation. The third moment of the article is dedicated to thinking of the insurrections of the rights of the governed as strategies of resistance to the processes of governalization of life. Our concluding remarks point to the tensions of the insurrections of the ruled as a way of life contrary to the economic guidelines of governmentality and biopolitics, through what Foucault calls the spiritual politics of revolt.
\end{abstract}

Keywords: Governed rights; Michel Foucault; Biopolitics; Governmentality. 


\section{Resumen}

Nuestro artículo busca pensar los derechos de los gobernados en Foucault como una crítica de la gubernamentalidad y la biopolítica. Se presenta una breve exposición sobre las posibles correlaciones entre la política de gubernamentalidad y los procesos de conducta producidos por las prácticas reflejadas del gobierno. Destacamos ainda el surgimiento de la biopolítica y los modos de conducta del liberalismo y el neoliberalismo, en la formación, de lo que Foucault llama la modulación del modos de subjetivación económicos. El tercer instante, es dedicado a pensar en las insurrecciones de los derechos de los gobernados como estrategias de resistencia a los procesos de gobernabilidad de la vida. Nuestras observaciones finales señalan las tensiones de las insurrecciones de los gobernados como una forma de vida contraria a las pautas económicas de la gubernamentalidad y la biopolítica, a través de lo que Foucault llama la política espiritual de la revuelta.

Palabras clave: Derechos de los governados; Michel Foucault; Biopolítica; Gubernamentalidad.

\section{Introdução}

O texto que ora apresentamos possui por finalidade estabelecer uma leitura sobre os direitos dos governados em Michel Foucault como uma crítica à governamentalidade e à biopolítica. Em linhas gerais, nosso artigo é norteado pela pergunta: os direitos dos governados compreendem uma alegoria de outros processos de subjetivação responsáveis por operar a suspensão dos dispositivos da biopolítica e da governamentalidade? Essa hipótese está diretamente relacionada a quatro pontos específicos que apresentamos a seguir: em primeiro lugar procuramos analisar como, nas pesquisas desenvolvidas por Foucault, os direitos dos governados acabam por constituir uma política de resistência para além dos dispositivos de poder.
Em segundo lugar, ele demonstra como tais práticas provenientes dos governados podem ser compreendidas a partir de uma leitura das insurreições, constituindo-se, desse modo, como uma crítica à governamentalização da vida e da biopolítica. Em terceiro lugar, ele procura compreender como os direitos dos governados, os modos de resistência e as insurreições se constituem por meio de modos de subjetivação, ou seja, formas de vidas cujas experiências são propostas por Foucault em relação à vida militante desdobrada na parresía dos governados. Por fim, exploramos os contornos dos direitos dos governados a partir do que denominamos de política espiritual da revolta.

Para uma História Política da Governamentalidade em Michel Foucault 
$\mathrm{Na}$ quinta aula de Segurança, Território, População, Foucault (2011) trata de deixar claro que o conceito de governo deve ser compreendido a partir de uma ampla perspectiva que envolve desde os aspectos institucionais da preservação das leis e das garantias cívicas, até as questões que percorrem o controle das condutas conforme se lê a seguir:

\footnotetext{
Gostaria de começar a percorrer um pouco a dimensão do que eu chamei com esta feia palavra que é "governamentalidade" (em aspas no original). Supondo-se portanto que "governar" não seja a mesma coisa que "reinar", não seja a mesma coisa que "comandar" ou "fazer a lei"; supondo-se que governar não seja a mesma coisa que ser soberano, ser suserano, ser senhor, ser juiz, ser general, ser proprietário, ser mestreescola, ser professor; supondo-se portanto que haja uma especificidade do que é governar, seria preciso saber agora qual é o tipo de poder que essa noção abarca (Foucault, 2011, p. 155-156 - Destaques no original).
}

O ponto de partida dessa governamentalidade seria um acontecimento singular na nossa sociedade a partir da emergência do que Foucault (2014) chama de poder pastoral. Uma economia de poder responsável por deslocar os efeitos das leituras políticas sobre o papel da soberania, para o problema de governo ético dos modos de subjetivação. De acordo com Candiotto
(2008), o poder pastoral institui a tese de que não é somente um território, nem uma estrutura que se governa, mas sim os sujeitos, ou como lembra Foucault (2011, p. 164): “(...) os homens é que são governados".

Um dos traços fundamentais para a potencialização do poder pastoral seria o dispositivo sacrificial a partir de um conjunto de apontamentos elaborados por Michel Foucault. Por exemplo, em Omnes et Singulatim, como em Segurança, Território, População, Foucault (1994a/2011) trata de estabelecer uma genealogia do poder pastoral a partir do seguinte quadrilátero: em primeiro lugar, ele é antiterritorial, por excelência, ou seja, o poder pastoral não se preocupa com a expansão imperial como outras modalidades de governo, já que ele se efetiva pelo que Bütten (2007, p. 1132) chama de “(..) multiplicidade em movimento". Em segundo lugar, o pastor é responsável pelo agrupamento do seu rebanho. Desse modo, o bom pastor é aquele que consegue agir rapidamente no sentido de aglutinar, no menor tempo possível, o maior número de ovelhas. Em terceiro lugar, diferentemente de outras modalidades de governo, o poder pastoral se preocupa em uma benevolência constante e individualizada sobre os sujeitos. Por fim, o poder pastoral deve exercer a vigília das almas como regra de um fundamento ético voltado para a devoção permanente e 
irrestrita do rebanho perante a autoridade pastoral.

Essas características do poder pastoral devem ser lidas não tanto pelas suas raízes teológicas e simbólicas, mas sim pelo fato de que tal dispositivo se configura como uma prática refletida de governo responsável por explicitar que todo o rebanho pode ser sacrificado para que uma ovelha seja salva a partir desse regime de governamentalidade. Essa condição, conforme lembra Foucault (2011), constitui-se como a arte das artes a partir do governo das almas da qual é testemunha a pastoral cristã.

A questão a ser abordada dentro dessa perspectiva corresponde à manifestação da verdade como elemento intrínseco ao governo dos homens e à prática aletúrgica de uma genealogia do indivíduo moderno. É no interior dessa relação que se encontra o problema do governo dos vivos, compreendido a partir dos procedimentos de verdades presentes no cristianismo e suas múltiplas experiências de manifestações da tecnologia do poder pastoral.

Conforme aponta Foucault (2011), a tecnologia de poder pastoral produz um sentido específico para o governo das condutas compreendendo-as como uma estratégia ética desdobrada na capacidade do sujeito ser conduzido por um sistema de regramento voltado para a sua salvação. Isso significa que devemos entender a introdução da noção de conduta como uma finalidade ética, cujo impacto sobre a governamentalidade compreende a necessidade de se procurar aperfeiçoar constantemente a direção do rebanho em relação aos traços fundamentais de um regime que opera nos contornos de uma vida pacientemente calculada e instrumentalizada pelos dispositivos de assujeitamentos.

Estamos diante de um problema ético fundamental criado pelo cristianismo por meio da formulação do seguinte questionamento: como e sob quais condições determinada arte de governo deve ser intensificada? Pergunta esta que coloca em evidência a compreensão, por parte de Foucault de que

\footnotetext{
A conduta é, de fato, a atividade que consiste em conduzir, a condução se vocês quiserem, mas é também a maneira como uma pessoa se conduz, a maneira como se deixa conduzir, a maneira como é conduzida e como, afinal de contas, ela se comporta sob o efeito de uma conduta ou de condução (Foucault, 2011, p. 255).
}

Nesse sentido, o poder pastoral assinalado por Foucault situa as práticas de gestão das almas, associadas à gestão das crises éticas, políticas e econômicas. Emblema este que foi responsável pela instauração do declínio do poder pastoral. Tal problema acaba por sinalizar as possíveis pistas deixadas por Foucault em 
relação a uma possível genealogia dos modos de insurreição e, nesse contexto, emergem as condições de possibilidades para situarmos uma crítica em relação aos modos de governo por meio da visualização de estratégias de sublevação de forças, no sentido de questionarmos as formas de governamentalidades, a partir da colocação do problema de governo compreendido como um ethos, uma forma de vida. Essa genealogia das práticas de insurreição corresponde, portanto, a alternativa para pensarmos não somente a estruturação de um projeto revolucionário, mas a possibilidade de questionarmos o sentido ético das formas de governo da vida. A respeito da crítica foucaultiana ao problema da revolução, constata-se, ainda nas primeiras páginas de $O$ Governo de Si e dos Outros, o questionamento por parte de Foucault (2008) se não estaríamos assistindo - desde o final do século XX- ao esgotamento da idade da revolução, ou seja, se os acontecimentos políticos da nossa contemporaneidade não colocam sob suspeita o monopólio ocidental do desejo revolucionário no seu sentido tradicional. É justamente em torno dessa contextualização que Foucault desenvolve um olhar cético sobre o papel tradicional em torno dos habituais enunciados nos quais se encontram os projetos revolucionários, deslocando seus efeitos para as políticas da insurreição.
A insurreição não é um sonho distante, mas um embate no qual está em jogo a maneira pela qual a insurgência dos governados corresponde a uma disputa permanente para converter os acossamentos dos dispositivos de governo em formas de existências autênticas.

É importante destacarmos, conforme lembra Avelino (2016), que não somos o resultado de um processo evolutivo de afirmação do Estado soberano tão somente. $\mathrm{Na}$ realidade, o que emerge é um princípio de deslocamento ético e político por meio do qual o sentido de se governar passa a se configurar, paulatinamente, em uma atividade a fim de garantir a preservação da população nos territórios por meio dos dispositivos de segurança econômica. Não por acaso que o grande emblema da razão de Estado a partir do século XVI será o de intensificar os procedimentos necessários para que a segurança seja sempre a meta por excelência a ser alcançada dentro do panorama de qualquer governo. Conservação, portanto, dos elementos da razão de Estado que consiste em nos fazer acreditar na segurança como vontade intrínseca de se pertencer à determinada forma de controle. É por conta desse traço que a razão de Estado não se ocupa em resolver todos os problemas, conflitos e contradições existentes na nossa sociedade. Não há, portanto, na razão de Estado qualquer projeto utópico de redenção 
messiânica em seus procedimentos de governo, muito embora os seus procedimentos metodológicos se inscrevam a partir dos problemas lançados pelo poder pastoral.

\section{A Biopolítica Como Paradigma de} Governo

A leitura de o Nascimento da Biopolítica (Foucault, 2012)pode frustrar um leitor mais engajado do pensamento foucaultiano, pois em pouco mais de quatrocentas páginas a menção ao conceito de biopolítica é raramente evocada. Citaremos duas possíveis razões para essa atitude. A primeira delas se encontra amparada na recusa, por parte de Foucault (2012), em reduzir todo o conjunto de problematizações e métodos por ele estruturado a uma teoria do poder Já a segunda se refere ao panorama político à época em que esse curso foi ministrado, cujo contexto compreendia tanto o esgotamento do império soviético, como a ascensão dos governos neoliberais de Ronald Reagan e Margareth Thatcher.

Ou seja, após o nascimento do liberalismo a biopolítica se desdobra no horizonte de uma grade de inteligibilidade de uma economia política da verdade. Isso significa que as condições de possibilidades desse novo estilo de governo se ocuparão em não mais assegurar o crescimento do Estado, mas limitar no seu próprio interior qualquer possibilidade de intervenção por meio da formulação do enunciado de que nunca se deve governar demais. Para Senellart, o liberalismo põe em cena o fato de que se deve sempre perguntar

Como governar, contudo, se se governa demais? Tal é, para Foucault, a questão que faz do liberalismo uma prática de governo original, ligada, em seu funcionamento, à crítica permanente de si mesma. É por esta razão que ele vê nela "uma formação de reflexão crítica sobre a prática governamental" (Foucault, 1990, p. 116). Crítica não somente das práticas despóticas do Estado absoluto, mas da própria racionalidade de governo, como princípio que estrutura a sociedade (Senellart, 1995, p. 08. Destaques no original).

Percebe-se que, nesse caso, com a emergência da governamentalidade liberal, inicia-se um grande campo de disputas entre as diferentes estratégias que colocam em relevo não mais o problema do gerenciamento do Estado como categoria fundamental, mas sim as diferentes manifestações de interesses dos modos de subjetivação. Nesse contexto, o problema essencial para Foucault (2012) não consiste mais - pelo menos desde o aparecimento da 
biopolítica - na promessa da grande utopia revolucionária que acenava com as diretrizes necessárias para a derrubada do Capital e do Estado e a instauração de uma outra realidade. O que está em jogo é percebermos como o liberalismo abre a perspectiva de pensarmos as rupturas a partir do questionamento político e ético sobre quais as emergências e proveniências das formas de governamentalidades nos foram impostam há séculos. Baseados na tese foucaultiana de que a razão governamental inaugura, desde o final do século XVIII, um processo de radicalização da utilidade quanto aos seus procedimentos governamentais, a nossa tarefa consiste em percebermos que se por um lado a vida das populações tem sido regrada por uma lógica do mercado como instrumento orgânico de ajustamento das condutas, por outro lado essa mesma governamentalidade nos mostra como podemos proceder o agenciamento de outras modalidades de governo ou pelo menos buscarmos por outras perspectivas que desafiam o estilo de vida da modalidade liberal dentro do seu próprio terreno.

A esse respeito apontam Lemos, Galindo e Nascimento (2016) que tal acontecimento deve ser lido como a modulação das condutas correlativa à mercantilização dos processos de subjetivação. Ora, o que procuramos afirmar, segundo as orientações de Foucault (2012), é que com o liberalismo se inicia não apenas o processo de mercantilização da economia, mas também os efeitos de uma mercantilização da subjetivação prostrada por um modelo de biopolítica amplamente consolidado em uma governamentalização de uma ética de mercado levada ao extremo pelos preceitos da liberdade econômica.

O neoliberalismo nada mais é do que um herdeiro macabro das tradições liberais dando novo sentido à economia de mercado. Isto é, o neoliberalismo é uma prática de governo que coloca o emblema da livre iniciativa e do empreendimento de si mesmo como a única garantia contra qualquer forma de autoritarismo. Conforme se pode observar, Foucault (2012) acaba por nos indicar que o estudo das emergências e das proveniências do neoliberalismo, acaba por colocar em evidência a perspectiva de pensarmos os modos pelos quais somos assujeitados a um modelo de governamentalidade segundo o qual a única compreensão possível de liberdade é aquela produzida pela flutuação das regras de mercado.

O que está em jogo nesse processo é a conduta promovida pelo neoliberalismo. Uma conduta econômica que mobiliza o regime de governamentalidade a partir da constatação de que essa ética da biopolítica já não pode mais ser caracterizada pela tipologização do sujeito. Não se trata mais de prescrever formas de subjetividades como anormais - as figuras do criminoso, do 
louco, do homossexual - mas procurar contornar os mapeamentos econômicos das condutas individuais, como se fosse possível articular aos pressupostos da biopolítica os elementos e as regras da lei da oferta e da procura para o contexto das práticas sociais.

Trata-se, portanto, de uma curvatura ética representada pelo homo oeconomicus: a tese de que a governamentalização das condutas não depende mais da secularização dos dispositivos disciplinares, mas sim dos regramentos provenientes dos modos de veridicção nos quais essa figura se encontra situada. Nesse sentido, ao operar uma leitura da biopolítica como grade de inteligibilidade do processo de governamentalização neoliberal, Foucault acaba por nos indicar que o grande desafio à construção de uma crítica em relação à razão de Estado repousa no diagnóstico das condições de possibilidade das formas de governamentalidade às quais somos assujeitados desde a emergência do poder pastoral, passando pela razão de Estado e culminando com as emergências e proveniências tanto do liberalismo, quanto do neoliberalismo. Essas seriam as ferramentas apresentadas por Foucault (2012) no sentido de pensarmos uma história do tempo presente sinalizadas nas possíveis fissuras e estratégias de resistências ligadas à perspectiva dos direitos dos governados.

\section{Dos Direitos dos Governados em Michel Foucault: Crítica à Governamentalidade e Genealogia das Práticas de Insurreição}

Conforme podemos observar, o estatuto da governamentalidade neoliberal desconhece outro caminho que não o da modulação econômica da subjetividade para o exercício de práticas refletidas de governo a serviço das corporações e das taxações provenientes dos sistemas de endividamento públicos e privados.

A esse respeito, Nalli (2012) nos aponta que os desdobramentos da biopolítica enquanto estratégia de gerenciamento da população, oportuniza com que pensemos as resistências de uma prática política contrária à normalização da vida, pois como afirma o Comitê Invisível (2016, p. 76) “(...) o contrário da democracia não é a ditadura, mas a verdade”. Nesse sentido, é impossível não pensarmos uma genealogia das práticas de insurreição dos governados, sem que percebamos o seu papel fundamental, qual seja, o de colocar no centro dos debates políticos da atualidade, o estatuto da governamentalidade neoliberal. Governamentalidade esta que, diante do atual cenário da chamada crise das democracias ocidentais, efetiva-se como a estratégia de condução, por excelência, da população, objetivando maximizar sua potencialidade induzindo-as ao desejo da liberdade econômica tão somente. 
Nesse sentido, dentro de um quadro geral de uma história política da governamentalidade, os direitos dos governados se situam nos interstícios de todos os traços de gerenciamento dessa mercantilização da conduta humana. Emergem, dessa maneira, as insurreições como uma crítica presente nos próprios procedimentos de governamentalização da vida, pois não podemos pensar os traços dessa racionalidade neoliberal que confere à crise um instrumento de controle, sem pensarmos a operatividade de outras formas de governo a partir de estratégias de resistências. Ao se apresentar como lugar de verdade, a governamentalidade neoliberal se coloca diante de um novo desafio: “(...) se há uma economia política, o que acontece com o direito público? (Foucault, 2012, p. 52) "tal pergunta nos auxilia a perceber como e sob quais condições as insurreições compõem o performático jogo dos modos de veridicção. As insurreições interpelam, dessa forma, a governamentalidade neoliberal a partir da instituição de novas verdades éticas e políticas. No limiar da crise neoliberal emergem, portanto, outras práticas de verdades. As experiências de uma política e uma ética menores ou, como aponta Pelbart (2012), a biopolítica dos resistentes, implica na problematização dos efeitos nefastos da racionalidade neoliberal a partir de novos modos de subjetivação e seus desdobramentos no tempo presente.
É diante de tal perspectiva que podemos reconhecer nos dois últimos cursos ministrados por Foucault (2008/2009) no Collège de France - Governo de Si e dos Outros e A Coragem da Verdade, respectivamente - os elementos necessários para uma ilustração dos direitos dos governados como uma crítica em relação à governamentalização da vida produzida pelo neoliberalismo e a modulação de uma subjetivação econômica produzida pela biopolítica.

Chama-nos atenção $o$ fato de Foucault (2009) reconhecer nas práticas refletidas de governo anteriores ao poder pastoral os elementos de uma estratégia ética e política que acaba por produzir as fissuras necessárias às práticas refletidas de governo aos quais somos assujeitados.

Conforme aponta Foucault (2009), tanto o discurso revolucionário quanto o discurso filosófico e o discurso científico se colocam como emblemas da parresía no momento em que se problematiza uma determinada condição de problematização da governamentalidade e da biopolítica. Mais especificamente, no contexto do discurso revolucionário, esse ato envolve a recusa em se assujeitar perante determinadas formas de governo. Na opinião de Marzocca (2013), a parresía designa uma atitude para a prática revolucionária por meio da radicalização da democracia. Tal constatação nos leva a perceber as 
ressonâncias dessa perspectiva já que a coragem da verdade é de fundamental importância para que o jogo democrático não se torne apenas uma prática burocrática e aparentemente representativa. Mais do que nunca a prática revolucionária nos mostra que uma democracia precisa ser pensada a partir de uma experiência voltada não para a hegemonia das identidades, mas sim pela afirmação da diferença.

Eis o efeito paradoxal das insurreições. Elas fazem parte de um movimento histórico dos desdobramentos sociais e, ao mesmo tempo, proliferam-se em contínuos deslocamentos. Ou seja, elas nos ensinam a perceber que toda forma de biopolítica e de governamentalidade encontra o seu esgotamento assim como é precisamente nesse instante que diferentes formas de vida travam um embate cujo pano de fundo é o problema do governo da vida. Vidas em risco, mas acima de tudo, vidas em jogo, pois por mais absoluta que seja nenhuma forma de biopolítica e de governamentalidade pode barrar uma insurreição.

Para ilustramos essas questões no contexto dos direitos dos governados devemos, necessariamente, problematizar e discutir os efeitos transversais das práticas dos insurgentes a partir da espiritualidade. Entretanto, por espiritualidade Foucault (2009) não entende uma prática transcendental, mas o conjunto de procedimentos de uma ascese política que não reivindica a conscientização coletiva das classes, mas se detêm sobre a capilaridade dos agenciamentos em que os direitos dos governados se efetivam como uma máquina de guerra. Dessa maneira, a sustentação política dos direitos dos governados se aproxima da concepção de uma política espiritual da revolta, na medida que tensiona os modos de verdade dos dispositivos governamentais.

Tal qual assinala Foucault, há uma espécie de permuta entre a política espiritual da revolta e as práticas dos governados, pois essas experiências procuram não mais reivindicar o espaço de representatividade e de visibilidade dos habituais contornos da política, mas capturar nos entre lugares dos modos de governamentalização da vida as questões que envolvem os agenciamentos da infâmia. É nessa perspectiva que as insurreições tomam corpo por meio de uma máquina de guerra, cujo procedimento consiste em se chocar permanentemente contra os dispositivos. Seja pelas pequenas táticas de bloqueio, seja pelas passeatas, seja pela proliferação de textos consagrados à conspiração contra as diretrizes governamentais, seja pelo simples gesto de afirmar: Já basta! Não toleraremos mais o intolerável. $^{2}$

Os direitos dos governados se situam, portanto, nos desdobramentos históricos a partir das práticas dessas vozes 
descentralizadas e transversais por meio das quais os insurgentes não se encontram localizados na universalização das racionalidades governamentais, mas sim nos traços de singularidades presentes em gestos polêmicos, em fissuras ritualísticas que contrapõem as normalizações. Desse modo, o problema reside em percebermos como a experiência dos governados é uma prática ascética de uma política espiritual da revolta estruturada pelo enfrentamento cotidiano aos modos de governo que pretende capturar a vida.

A respeito do grave problema da crise migratória nos países europeus Foucault redige um pequeno manifesto acerca do tensionamento existente entre os dispositivos de governo e uma nova prática do direito.

Depois de tudo, somos todos governados e, sob este título, solidários. Porque pretendem ocupar-se da felicidade das sociedades, governos arrogam-se o direito de passar à conta dos lucros e perdas a infelicidade dos homens que suas decisões provocam e que suas negligências permitem. É um dever dessa cidadania internacional sempre fazer valer, aos olhos e ouvidos dos governos, as infelicidades dos homens pelas quais são responsáveis. A infelicidade dos homens não deve jamais ser um resto mudo da política. Ela funda um direito absoluto de levantar-se e dirigir-se àqueles que detêm o poder. É preciso recusar a divisão de tarefas que, muito frequentemente, propõe-nos: aos indivíduos, indignar-se e falar; aos governos refletir e agir. É verdade: os bons governos, gostam da santa indignação dos governados, por mais que permaneça lírica. Creio que é preciso dar-se conta de que, muito frequentemente, são os governos que falam, só podem e querem falar. (...) A vontade dos indivíduos deve inscrever-se em uma realidade de que os governos quiseram reservar-se o monopólio, esse monopólio que é preciso arrancar pouco a pouco e a cada dia (Foucault, 1994b, p. 707-708).

Essa perspectiva adotada por Foucault em relação à luta política empreendida pelos governados, sem sombra de dúvidas faz emergir uma condição histórica dos agenciamentos políticos da nossa atualidade. Entretanto, tal perspectiva não se inscreve em uma alegoria das instâncias jurídicas e normativas tradicionais. A prática dos direitos dos governados reflete uma resistência política pela insurgência dos movimentos populares, dos bloqueios, das passeatas e das greves gerais captadas pelo olhar atento da genealogia. Acima de tudo, as provocações lançadas por Foucaultnos fazem perceber como a era da biopolítica abre uma dobra no que se refere às práticas de insurreição cuja constatação é: nenhum governo poderá -seja liberal, seja conservador - escapar das revoltas dos governados.

Neste sentido, as insurreições dos governados colocam como problema central à contemporaneidade os processos de 
subjetivação a partir das crises abertas pelos múltiplos programas de governo. $\mathrm{O}$ fundamento de tais práticas está amparado em uma espécie de triplo efeito segundo o qual os governados problematizam os jogos de verdade, as práticas de governo e a própria constituição de si mesmo como sujeito. Esse triplo efeito faz circular as resistências pelas práticas de veridicção por meio do constante questionamento aos dispositivos de controle e governança. Quando um militante vem a público proferir determinada verdade está interessado em apresentá-la como um ethos, as razões pelas quais ele acredita que deve rebelar-se contra a governamentalidade, pois segundo aponta Gros

\begin{abstract}
A insurreição não se decide. Apodera-se de um coletivo, quando a capacidade de desobedecer juntos volta a ser sensível, contagiosa, quando a experiência do intolerável se adensa até se tornar uma evidência social. Supõe a experiência prévia compartilhada -mas que ninguém se pode dispensar de viver em, por e para si mesmo - de uma dissidência cívica e de seu apelo (Gros, 2018, p. 17).
\end{abstract}

Essas perspectivas ilustram o fato de que as insurreições dos governados vão além de um mero confronto contra os mecanismos de opressão, como também dos aparatos ideológicos, mas pela inscrição em torno dos procedimentos de governo. Uma vez que os procedimentos de governamentalização interpelam o sujeito a dizer a verdade sobre si mesmo, a compreensão de um panorama político sobre a heterotopia dos governados significa pensar os efeitos dos espaços de resistências. Ou seja, os diferentes procedimentos pelos quais as insurreições interpelam a própria governamentalidade. Pois, mais do que nunca, o combate ao excesso de governo se configura como emblema da nossa sociedade. Desde as crises abertas pelo poder pastoral, passando pela razão de Estado e pelo próprio liberalismo econômico reside a tese de que nenhuma forma de governo pode vigiar e controlar sem que as contra condutas lhes imponha uma série de questões.

\section{Considerações finais}

Nas duas primeiras aulas de $O$ Governo de Si e dos Outros Foucault (2008)sublinha que o texto escrito por Kant (2004) - Was ist Aufklärung - é uma possível ilustração das estratégias de resistências dos governados a partir das contracondutas. Dentre as condições de possibilidades desse escrito, encontra-se a tese de que ele é responsável por inaugurar uma reflexão sobre a noção de Publikum, pois de acordo com Foucault:

Convém manter presente no espírito esse lugar de publicação - isto é, uma revista -, 
pela razão seguinte. É que, como vocês vão ver, esse texto sobre a Aufklärung aplica, como um dos seus conceitos centrais, a noção de público, de Publikum. E por essa noção de Publikum entende: primeiro a relação concreta, institucional, ou em todo caso instituída, entre o escritor (o escritor qualificado, traduz-se em francês: savant; Gelehrter: homem culto) e o leitor (o leitor considerado como indivíduo qualquer). E é a função dessa relação entre leitor e escritor, é a análise dessa relação - as condições em que essa relação pode e deve ser instituída e desenvolvida - que vai constituir o eixo essencial da sua análise da Aufklärung (Foucault, 2008, p. 09).

Ou seja, trata-se de uma tipologia na qual podemos encontrar, na relação entre o intelectual e o público leigo, os elementos de uma atividade prática em torno de uma história do tempo presente. Nesse sentido, direcionar os olhos para a atualidade significa percebermos os desdobramentos daquilo se vive. Dos tensionamentos existentes como uma espécie de jogo de espelhos no qual não podemos nos furtar em respondermos as atribuições políticas, econômicas, sociais e culturais disso que chamamos contemporaneidade.

Ontologia histórica de nós mesmos como emblema dos direitos dos governados, portanto. Uma atitude e uma interrogação sobre as nossas condições a partir da constatação de que o fundamento das práticas dos governados se desdobra perante os modos de subjetivação de outras formas de vida. De fato, quando pensamos os elementos de uma ontologia histórica de nós mesmos, não nos limitamos a percebermos as lutas políticas como um projeto revolucionário da tomada de consciência, mas sim uma questão muito mais pulverizada e que é atravessada sobre os processos de subjetivação compreendidos como uma atitude-limite perante os encantamentos das formas de governo. Em linhas gerais, o problema consiste em nos debruçarmos constantemente sobre a questão: quais linhas de fuga são construídas perante a governamentalização da vida? Se atentarmos para o fato de que a resistência não é somente um gesto espontâneo, talvez o grande problema das insurreições seja o de justamente percebermos como é necessário compreendermos as condutas dos governados como elementos de outras experiências de vida. Pois, em uma sociedade neoliberal que confere à economia o modelo de modulação das estratégias de saber, das práticas de poder e dos processos de subjetivação, por excelência, os direitos dos governados se efetivam como uma busca incessante, por parte dos sujeitos, em efetivar um autogoverno. Autogoverno este que encontra suas verossimilhanças nas atitudes performáticas que nos lembram constantemente o seguinte enunciado: ilegítimo não são os governos, mas a maneira pela qual nos deixamos, por 
vontade própria, ser dependentes das arbitrariedades dos dispositivos de gerenciamento da nossa própria vida.

Um estudo sobre os direitos dos governados em Michel Foucault compreende, portanto, a sublevação dessas forças, desses devires. Fazendo do direito não um estatuto normativo de preservação natural das garantias fundamentais tão somente, mas $\operatorname{sim}$ a radicalização das emergências e proveniências das vozes infames. Entretanto, tal problema recai sobre a condição de se colocar em evidência o papel da revolução. Não se trata em absoluto de compreender quais elementos se tornam necessários para a sua preparação, como um projeto teleológico, mas sim perceber que a revolução está entre nós, pois, desde o poder pastoral até a consolidação do projeto neoliberal, sempre existiram formas de vida que recusaram ser conduzidas e são essas formas de vida que interessam a um projeto crítico de contextualização das lutas orquestradas pelos governados.

O gerenciamento da vida, a modulação dos modos de objetivação e de subjetivação que assistimos, colocam em evidência as contra condutas como práticas transgressivas, como estratégias de resistências e como práticas de liberdades. Dito de outro modo, se o problema da governamentalidade é conduzir a partir das crises, entram em cena as necessidades de problematização das práticas refletidas de governo. E tal perspectiva acaba por indicar que os direitos dos governados são uma luta pela vida. Uma vida menos ordinária, menos cafetinada, menos fascista. Trata-se de um processo de fruição que problematiza constantemente os traços de controle dos dispositivos.

Dessa maneira, no sentido de procurarmos pensar os elementos apresentados como hipóteses do nosso trabalho cumpre ressaltar que a análise foucaultiana sobre os direitos dos governados tensionam os efeitos pelos quais as vozes insurgentes produzem uma nova política de resistência para além dos dispositivos jurídicos. Da mesma maneira, todo o conjunto de práticas de resistências provenientes dos direitos dos governados acabam por sinalizar os traços pelos quais as insurreições se apresentam como fissuras em relação ao gerenciamento da vida orquestrado tanto pela governamentalidade quanto pela biopolítica. Como terceiro traço dessas hipóteses constatamos que existe uma correlação entre as práticas dos direitos dos governados, os modos de resistência e as insurreições analisadas por Foucault. Essa correlação tensiona, por sua vez, os modos de subjetivação e a constituição de formas de vidas cujas ressonâncias se inscrevem, nos dias atuais por meio do ascetismo militante e da parresía dos governados. Esses dois traços constituem, aos olhos de Foucault, o modo de ser das práticas de 
resistência dos governados. Por fim, cumpre ressaltar que as práticas de resistências dos governados, ao constituírem-se como uma forma de vida, podem ser entendidas como uma política espiritual da revolta e, nesse sentido, apresentam-se como um tensionamento da própria política e da ética na nossa contemporaneidade.

\section{Referências}

Büttgen, P. (2007). Théologie Politique et Pouvoir Pastoral.Annales: historie, sciences sociales. Éditions de l'EHESS. 62, 1129-1154. Recuperado de https://www.cairn.info/revueannales-2007-5-page-1129.htm\#

Candiotto, C. (2008). Governo e direção de consciência em Foucault. Natureza Humana. 10(2), 89-113.Recuperado de http://pepsic.bvsalud.org/pdf/nh/v10n2/ v10n2a04.pdf

Comitê Invisível. (2016).Aos Nossos Amigos: crise e insurreição. São Paulo: $\mathrm{N}-1$.

Foucault, M. (1994a). Omnes et Singulatim: towards a criticism of political reason. In: Foucault, M.Dits et Ecrits IV: 19801988. (pp. 134-161). Paris: Quarto Gallimard.

Foucault, M. (1994b). Face Aux Gouvernements, les Droits le L'homme.Foucault, M. Dits e Écrits IV: 1980-1988.(pp. 707-708). Paris: Gallimard.

Foucault, M. (2008).O Governo de Si e dos Outros. São Paulo: Martins Fontes.
Foucault, M. (2009). A Coragem da Verdade. São Paulo: Martins Fontes.

Foucault, M. (2011).Sécurité, Territoire, Population. Paris: Gallimard.

Foucault, M. (2012).Nascimento da Biopolítica. São Paulo: Martins Fontes.

Foucault, M. (2014). Sexualidade e Poder. In: Foucault, M. Michel. Ditos $e$ Escritos V: Ética, Sexualidade, Política. (pp.55-75). Rio de Janeiro: Forense Universitária.

Gros, F. (2018).Desobedecer. São Paulo: Ubu Editora.

Kant, I. (2004).Was ist Aufklärung? Utopie Kreative.159, 5-10.Recuperado dehttps://www.rosalux.de/fileadmin/rls uploads/pdfs/159_kant.pdf.

Lemos, F. C. S. Galindo, D. Nascimento, M. L. (2016). Considerações Sobre o Empresariamento da Vida. Barbarói. 46 , 06-21.Recuperado de https://online.unisc.br/seer/index.php /barbaroi/article/view/5564/5992

Marzocca, O. (2013). Philosophical Parrêsia and Transpolitical Freedom. Foucault Studies. 0(15), 129-147. Recuperado de https://rauli.cbs.dk/index.php/foucaul t-studies/article/view/3994/4396

Nalli, M. (2012). A imanência normativa da vida (e da morte) na análise foucaultiana da biopolítica: uma resposta a Roberto Esposito. O Que Nos Faz Pensar. 21(31), 127152.Recuperadode http://oquenosfazpen sar.fil.puc-

rio.br/import/pdf_articles/OQNFP_31_9 _marcos_nalli.pdf

Pelbart, P.P. (2012). Foucault Versus Agamben? Revista Ecopolítica. 5, 5064.

Recuperado 
de https://revistas.pucsp.br/ecopolitica/a rticle/view/14983/11181

Senellart, M. (1995). A Crítica da Razão Governamental em Michel Foucault. Tempo Social. 7(1-2), 01-14. Recuperado de https://www.scielo.br/pdf/ts/v7n12/0103-2070-ts-07-02-0001.pdf

\section{Notas}

${ }^{1}$ Muitos são os intelectuais que ainda insistem em classificar $o$ pensamento foucaultiano dentro daquilo que ele recusou ao longo de toda sua trajetória intelectual e militante: os jogos de identidade. Esses intelectuais argumentam que o pensamento foucaultiano, influenciado pelas ideias de Nietzsche e Heidegger procura desconstruir um sistema epistemológico moderno inaugurando uma outra possibilidade de se problematizar as relações entre a subjetividade e o poder por meio de uma articulação da genealogia dos efeitos discursivos e das próprias relações de poder. Como se o pensamento foucaultiano fosse reduzido a uma dura crítica aos modos de sujeição presentes em discursos e práticas.

${ }^{2}$;Ya Basta! No dia 01 de Janeiro de 1994, o então autodenominado Exército Zapatista de Libertação Nacional, inicia uma insurreição contra o tratado de Livre Comércio da América do Norte e, mais especificamente contra o governo mexicano. O motim teve início no estado de Chiapas e os lemas dos zapatistas compunham um mosaico de reivindicações por Trabalho, Terra, Alimentação, Saúde, Educação, Independência, Liberdade, Democracia, Justiça e Paz. A partir desse levante têm-se início a um longo programa de reorganização da governamentalidade no território de Chiapas controlado pelos zapatistas em que se pode ler logo na entrada: Estad usted en territorio zapatista en rebeldia. Aqui manda el Pueblo y el gobierno obedece. Desse modo, podemos perceber que a insurreição zapatista é uma clara demonstração da busca por uma outra forma de governo. No caso, tal experiência de rebelião compõe a performatividade de militantes tomados pelo contagiante ideia da insurreição que procuram desencadear uma luta constante contra os processos de assujeitamentos da governamentalidade neoliberal.

Rodrigo Diaz de Vivar y Soler é bacharel em Psicologia pela UNESC, mestre em Psicologia pela UFSC e doutor em Filosofia pela UNISINOS. É também professor colaborador do mestrado em Educação e do curso de Psicologia pela FURB.

E-mail: diazsoler@gmail.com ORCID:https://orcid.org/0000-0001-72863129

Enviado em: 25/11/19- Aceito em: 02/09/20 